\title{
Effects of the Medium of Instruction in Comprehending Mathematical Word Problems
}

\author{
Jasmin M. Sumipo \\ Mater Dei College, Tubigon, Bohol, Philippines. \\ Email:_arleymine_1@yahoo.com
}

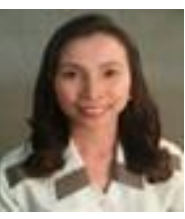

\begin{abstract}
This study aimed to determine the effects of the medium of instruction (MOI) used in teaching to the learners' ability to comprehend mathematical word problems. Additionally, the study aimed to find out whether there is a significant difference in the mathematical performance of public school learners who were taught using Cebuano as MOI compared with private school learners who were taught using English as MOI. Anchored on Common Underlying Proficiency Theory of Cummins, Meaningful Verbal Learning Theory of Ausubel and other related studies, this research sough to know how the language affects mathematics learning. The design used is a causal comparative between two elementary schools, one private and another public. Purposive sampling was used to get the top twenty learners from each class who were chosen as research participants. Using arithmetic mean, standard deviation, t-test and z-test formula, data were statistically treated. The findings revealed that the level of mathematics achievement of the learners of both private and public schools were higher using English rather than their mother tongue, Cebuano. Findings also revealed a significant difference in the performance of both groups of learners in the two types of questionnaires. Furthermore, no significant difference was found between the performance of private school learners compared to the public school learners. Thus, it can be concluded that the medium of instruction affects the comprehension of the learners in mathematical problem.
\end{abstract}

Keywords: Comprehension, Language and learning, Mathematics, Medium of instruction, Word problems.

JEL Classification: C02, I28.

Citation | Jasmin M. Sumipo (2020). Effects of the Medium of Instruction in Comprehending Mathematical Word Problems. Asian Journal of Social Sciences and Management Studies, 7(1): 58-61. History:

Received: 17 January 2020

Revised: 26 February 2020

Accepted. 30 March 9090

Accepted: 30 March 2020

Published: 16 Apil 2020 is licensed under a Creative Commons

Attribution 3.0 License (cc)

Publisher: Asian Online Journal Publishing Group
Funding: This study received no specific financial support.

Competing Interests: The author declares that there are no conflicts of interests regarding the publication of this paper.

Transparency: The author confirms that the manuscript is an honest, accurate, and transparent account of the study was reported; that no vital features of the study have been omitted; and that any discrepancies from the study as planned have been explained.

Ethical: This study follows all ethical practices during writing.

\section{Contents}

1. Introduction

3. Results and Discussion

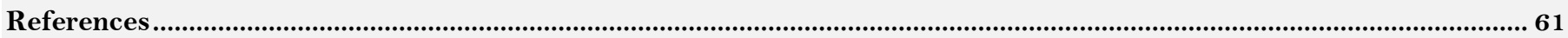




\section{Contribution of this paper to the literature}

This research sought to find out the effects of medium of instruction to learners' comprehension of mathematical world problems. Since the Philippine Department of Education issued Deped Order number 16, series of 2012, the government implemented the Mother Tongue-Based-Multilingual Education (MTB-MLE) in all public schools. This mandated the use of the mother tongue as medium of instruction in all subjects of learners from grades 1-3. Private schools, however, may opt to use English as medium of instruction, and only have MTB-MLE as a subject. This research proves that learners of both public and private schools got better scores in Mathematical test using English than the same test in Cebuano.

\section{Introduction}

Cummins Theory explains that by using the first language as the medium of instruction, bilinguals can easily learn and acquire academic skills. It also emphasized the purpose of language proficiency assessment in bilingual education which is the placement of learners to classes taught through the language which will best promote learning. This theory supports the idea that with the use of instructional medium that learners could easily learn, there is a high possibility that the learners could understand better, thus resulting to high performance of the learners.

Cummins (1984) suggests the Common Underlying Proficiency Theory which states that linguistics resources from learners first language(L1) helps in learning second language (L2). In other words, the set of skills learned in the L1 can be transferred to learners in acquiring the L2. These skills include the knowledge of language, literacy, and concepts learned in the first language can be drawn upon in the second language. In the same token, Ausubel's Theory of Meaningful Verbal Learning explains that effective instruction occurs when new information is associated with prior learning at every step in the process.

The MOI is important to effective mathematics instruction. In concurrence to this, Weinburgh, Silva, Smith, Groulx, and Nettles (2014) said that the wording used by both students and instructors in mathematics discourse influences the learning of mathematical principles. Similarly, Vukovic and Lesaux (2013) noted that language affects how students interpret mathematical ideas. It is therefore imperative to evaluate the effect of language factors on students' achievement in mathematics through measurement of language-related variables in test items and relating these measures to student performance (Toll \& Van Luit, 2014).

Mathematics vocabulary includes words that are specific to mathematics, such as divisor, denominator, quotient, and coefficient (Barwell, 2001). These words like many others have no equivalent in Cebuano dialect. Thus, teachers and students oftentimes resort to borrowing of the English terms or through "transliteration" wherein English words are phonetically translated into the Cebuano dialect. This has been the most common and convenient way of creating equivalent words from English.

According to Barwell (2001) without a personally constructed knowledge base of mathematics vocabulary, the task of reading a mathematics textbook, interpreting a teachers' instructional commentary, solving a word problem, or communicating one's own knowledge about mathematics to others becomes extremely difficult for students. Hence, it is primarily important that learners be taught in medium of instruction that feel comfortable to use.

Boulet (2007) is of the opinion that in the field of mathematics education there is a clear awareness for the need to account for connections between language and mathematics. Boulet also states that in order for teachers to reveal the reasons behind mathematical procedures, it is imperative for them to make use of clear language. Mathematical discourse includes specialist syntax, particularly in relation to the expression of logical relationships. Thus the use of and, of, or, a, if and then to define mathematical relationships are all significant. Such words, are, however, easy to overlook. Strategies to support the development of syntax could include the use of writing frames or partly structured sentences (e.g. matching a set of 'if clauses with a set of 'then' clauses).

\section{Methodology}

This study used causal-comparative research design where data is taken from the scores of two groups of top twenty grade 3 learners in two types of mathematical word tests (one in English and one in Cebuano). The participants of this study were the top twenty grade 3 Math achievers in of one public school and one private school of Tubigon, Bohol, Philippines. Moreover, this research sought to answer the following null hypotheses, 1.) there is no significant difference in the level of mathematics achievement in the two different mediums of instruction; and 2.) There is no significant difference in the mean achievement of learners in the private and public schools.

To answer the pertinent problems in the study, the researcher used a Mathematics achievement test in two different languages as the main tool. Since grades 1,2 and 3 learners of public schools are taught Mathematics using the mother tongue, in this case the Cebuano dialect, they were given the questionnaire in Cebuano first before the test questionnaire in English. While the grade 3 learners of private school who are taught using English were given the questionnaire in English first before the one in Cebuano. Statistical treatments used to analyze and interpret data included arithmetic mean, standard deviation, $\mathrm{T}$ test and $\mathrm{Z}$ test.

\section{Results and Discussion}

3.1. Levels of Achievement in Mathematics of Both Groups

The level of mathematics achievement of both groups of participants in both the Mathematical test in English and in Cebuano are presented in the first table. 
Table-1. Level of mathematics achievement.

\begin{tabular}{l|l|c|c|c}
\hline Participants & Medium of Instruction & Mean & Standard Deviation & Description \\
\hline \multirow{2}{*}{$\begin{array}{l}\text { Private School } \\
\text { Learners }\end{array}$} & English & 10.15 & 1.6311 & High \\
\cline { 2 - 5 } $\begin{array}{l}\text { Public School } \\
\text { Learners }\end{array}$ & Cebuano & 7.9 & 1.9167 & Average \\
\cline { 2 - 5 } & English & 10.3 & 1.5252 & High \\
\hline
\end{tabular}

Based on Table 1, the data revealed that both groups of learners had higher scores in mathematical questionnaires using the English language. Both private school and public school learners had a description of high in English and both also had an average description in Cebuano. This finding implies that learners can comprehend better if Mathematical word problems are given in English than in Cebuano which is contrary to the expectation that learners performed better in their first language than in their second language. A possible explanation to this finding is that these learners are exposed to English even at a young age. According to (Barwell, 2001) Mathematics have terms exclusive to the field. When this happens, teachers usually resort to borrowing of terms or transliteration. This process sometimes makes it more difficult for learners to comprehend mathematical word problems in Cebuano than in English. Moreover, Math textbooks and other learning materials are mostly written in English than in Cebuano. Hence, it is not unusual for the research participants to have better achievement in Mathematical word problems in English than in Cebuano.

3.2. Comparison between Mean Scores of the Two School between the Two Mediums of Instruction

The scores of each group in the mathematical test were added to come up with the mean scores of the two groups of participants in Mathematical problems given in both English and Cebuano.

\begin{tabular}{|c|c|c|c|c|c|c|}
\hline School & $\begin{array}{l}\text { Mean } \\
\mathrm{N}=40\end{array}$ & $\begin{array}{c}\text { Known } \\
\text { Variance }\end{array}$ & $\begin{array}{c}\text { Critical Z } \\
\alpha=0.05\end{array}$ & Computed Z & $\begin{array}{c}\text { Decision on } \\
\text { Null Hypothesis }\end{array}$ & $\overline{\text { Difference }}$ \\
\hline Private & 10.225 & 2.435256 & \multirow[t]{2}{*}{ \pm 1.959964} & \multirow[t]{2}{*}{5.756587903} & \multirow[t]{2}{*}{ Reject } & \multirow[t]{2}{*}{ Significant } \\
\hline Public & 8.10 & 3.015385 & & & & \\
\hline
\end{tabular}

In Table 2, the total mean score of the groups of participants in the Mathematical test using English was 10.225 with a known variance of 2.435256 while in the test using Cebuano, the mean score was 8.10 with known variance of 3.015385. Since it is two-tailed at 0.05 level of significance, the critical value was \pm 1.959964 . The computed $\mathrm{z}$ is 5.756587903 which is in the critical region. Thus, the decision is to reject the null hypothesis. The computation showed that there is a significant difference in the mean achievement of the two groups of learners using two different languages, the mother tongue Cebuano and the second language English. Thus, it can be concluded that the medium of instruction used in the Mathematical tests affects the ability of learners to comprehend mathematical problems given that the same items were used in the questionnaires.

\subsection{Comparison between Two Groups of Samples}

The role of language in comprehending mathematical has been established in many research studies. The language used by both teachers and students in learning significantly influences the learning of mathematical concepts (Vukovic \& Lesaux, 2013; Weinburgh et al., 2014). The findings of the present study implicates that the language used in Mathematical assessment had a great impact on participants' scores. Though the result ran contrary to the idea that students learn better if math is taught in their first language (Cummins, 1984) the findings proved that indeed there is a connection between language and mathematics (Boulet, 2007). Comparison between the Total Mean Scores of the Two Groups of Participants

The mean scores of both participants were compared in Table 3 to find out whether there is a significant difference between mathematical performance of public school leaners who were taught Math using Cebuano as MOI and private school learners who were taught Math using English as MOI.

Table-3. Comparison between the two groups of samples.

\begin{tabular}{c|c|c|c|c|c|c}
\hline School & Mean & $\begin{array}{c}\text { Standard } \\
\text { Deviation }\end{array}$ & $\begin{array}{c}\text { Critical T } \\
\boldsymbol{\alpha}=\mathbf{0 . 0 5}\end{array}$ & Computed T & $\begin{array}{c}\text { Decision on } \\
\text { Null Hypothesis }\end{array}$ & Difference \\
\hline Private & 18.05 & 2.892367 & \pm 2.02619 & -0.64102 & Accept & Insignificant \\
\hline Public & 18.60 & 2.521487 & & & \\
\hline
\end{tabular}

Table 3 showed the overall mean scores of both groups of participants in the two sets of questionnaires. The private school has a mean score of 18.05 with the standard deviation of 2.892367 while the public school has a mean score of 18.60 with a standard deviation of 2.521487. Since the test is two-tailed at 0.05 level of significance, the critical value is \pm 2.02619 . Using the $\mathrm{T}$ test formula for Independent samples, the computed $\mathrm{t}$ is -0.64102 which falls in noncritical region. Hence, the null hypothesis is accepted. This implied that there is no significant difference between the mean scores of the two groups of participants. Both public and private school learners have the same level of mathematical achievements in the test questionnaires using English and Cebuano. Worthy to note is the fact that while public school students were taught Mathematics using Cebuano dialect while private school students were taught Math using English, both groups of learners had better performance when Mathematical word test was written in English than when it was written in Cebuano. Language variables such as learners exposure to a specific language, non-translatable Math terms, and learners' preference may have played a significant impact on the results of this research study. Finally, other learning factors such as mastery of teachers and availability of materials which play a great role in Mathematics teaching and learning also have to be taken into future research studies. 


\section{References}

Barwell, R. (2001). Learning from listening: Talk in a multilingual mathematics classroom. NALDIC Occasional Paper 14. Watford: NALDIC Publications Group.

Boulet, G. (2007). How does language impact the learning of mathematics? Let me count the ways. Journal of Teaching and Learning, 5(1), 112 .

Cummins, J. (1984). Wanted: A theoretical framework for relating language proficiency to academic achievement among bilingual students. Language Proficiency and Academic Achievement, 10, 2-19.

Toll, S. W., \& Van Luit, J. E. (2014). The developmental relationship between language and low early numeracy skills throughout kindergarten. Exceptional Children, 81(1), 64-78.Available at: 10.1177/0014402914532233.

Vukovic, R. K., \& Lesaux, N. K. (2013). Investigating the ways language counts for children's mathematical development. Journal of Experimental Child Psychology, 115, 227- 244.Available at: 1016/j.jecp.2013.02.002.

Weinburgh, M., Silva, C., Smith, K. H., Groulx, J., \& Nettles, J. (2014). The intersection of inquiry-based science and language: Preparing teachers for ELL classrooms. Journal of Science Teacher Education, 25(5), 519-541.Available at: 10.1007/s10972-014- 9389-9. 